\title{
Right frontal stroke: extra-frontal lesions, executive functioning and impulsive behaviour
}

\author{
Morgana Scheffer ${ }^{1 *}$, Chrystian Kroeff ${ }^{1}$, Bibiana Gallas Steigleder ${ }^{1}$, Lidiane Andreza Klein², Rodrigo Grassi-Oliveira ${ }^{3}$ \\ and Rosa Maria Martins de Almeida ${ }^{1 *}$
}

\begin{abstract}
The aim of this study was to evaluate executive functioning (EF) and impulsiveness in three groups of people aged 30 to 79 years: post-frontal stroke $(n=13)$ and post-extra-frontal chronic stroke of the right hemisphere $(n=31)$ and control $(n=38)$. The years of education varied between the groups was as follows, frontal lesion group: $M=12$ $(S D=6.11)$; extra-frontal lesion group: $M=9.06(S D=4.94)$; and control: $M=9.61(S D=4.24)$ years. The following instruments were used: Behavioural Assessment Dysexecutive Syndrome, Wisconsin Card Sorting Test (WSCT), Barratt Impulsivity Scale, Impulsivity Evaluation Scale, Delay Descounting Task and Go/No-Go Task. We found differences in EF between the extra-frontal lesion group and the control group with respect to cognitive flexibility ( $p=.018)$; number of WCST trials $(p=.018)$; WCST perseverative errors $(p=.014)$ and omission by impulsivity errors on the go/no-go task for $250 \mathrm{~ms}(p=.008)$ and $1750 \mathrm{~ms}$ trials $(p=.006)$. The frontal lesion group made more errors of omission than the control group in the $1750 \mathrm{~ms} \mathrm{go/no-go}$ trials $(p=.006)$. These results suggest that extra-frontal lesions impair EF by influencing attentional impulsivity.
\end{abstract}

Keywords: Cerebrovascular disease, Cognition, Impulsive behaviour

\section{Background}

Executive functioning (EF) consists of several subcomponents aimed at the execution of a behaviour directed at targets (Stuss and Levine 2002) and it encompasses processes and functions such as inference, problem solving, planning, organisation, strategy, decision making, behavioural inhibition, verification and control, which support adaptive, flexible behaviour and are central to the control of information processing in the brain (Bilder 2012). There are several theoretical models of EF although there is no agreed formal definition of the concept (Jurado and Rosselli 2007) although it is generally accepted that EF is a multidimensional concept (Stuss and Levine 2002).

The neural circuitry involved in EF is complex and integrated and other cortical circuits structures may influence EF (Krause et al. 2012). Frontal lesions do not correspond exactly to an impairment in that region (Bartolomeu 2011; Krause et al. 2012; Thiebaut de Schotten et al. 2012). The

\footnotetext{
* Correspondence: scheffer.morgana@gmail.com; rosa.almeida@ufrgs.br ${ }^{1}$ Universidade Federal do Rio Grande do Sul-UFRGS, Porto Alegre, Brazil Full list of author information is available at the end of the article
}

components of EF which have been studied are: (a) problem solving, i.e., the ability to choose between alternatives and adapt to changes in instrumental contingencies; (b) planning, which is intimately related to successful goaldirected activity; (c) inhibitory control; (d) cognitive flexibility i.e., the ability to adjust cognition and actions to reflect changes in the environment (Diamond 2013); and (e) judgement (Robinson et al. 2014). Some theories related to EF unique control approach consider a main cognitive construct as essential for frontal lobe related cognitive processing. It has also been argued that EF is based on the primary functions of prefrontal cortex and thus represents a diverse set of interconnected processes (Kluwe-Schiavon et al. 2012).

Injury to frontal circuits may cause EF impairments, as well as changes in temperament, a tendency to perserveration and lack of impulse control (Brenan and Raine 1997; Radanovic and Mansur 2004; Zappalá et al. 2012). According to Barratt (1994), impulsivity is a multidimensional concept, encompassing failure of inhibitory control, rapid processing of information, search for novelty and inability 
to postpone reward. Barratt proposed a three-factor model of impulsivity: motor, attention and impulsivity by lack of future planning. Impulsivity can be measured using selfreport questionnaires, visual analogue scales and laboratory behavioural tasks, enabling the verification of the impulsive action, related to the lack of inhibitory behaviour, and the impulsive choice, related to decision making without possibility no proper deliberation (Broos et al. 2012).

Impulsivity has been associated with impaired EF and with a reduction in inhibitory behaviour (Cheung et al. 2004; Whitney et al. 2004). Different manifestations of impulsive behaviour may correspond to different neuropsychological constructs with specific anatomic correlates (Diamond 2013). It is therefore important to describe impulsive behaviour in terms of phenotypes and endophenotypes (Adinoff et al. 2007).

There an overlap between the brain circuitry - particularly in the frontal regions - between areas involved in decision making, planning and impulsive action (Bickel et al. 2012). Some subcomponents of EF are measured as part of this overlap, such as planning, cognitive flexibility, problem solving and inhibitory control. This was confirmed by analysis of the brain's functional connections in resting state, which showed that the frontal parietal and the anterior-dorsal anterior cingulateinsular circuits were involved in performance of tasks that involved impulsivity and EF (Li et al. 2013; Seeley et al. 2007). Therefore, it can occur coincidence in the brain regions activation in the moment of the evaluation of executive functions and impulsivity. Jodzio and Biechowska (2010) reported that performance on the Wisconsin Card Sorting Test (WCST) is associated with performance on tasks which measure impulsivity, such as the Go/No-Go Task. The WCST enables one to separate out the motor and attentional components of impulsivity, and these subtypes of impulsivity can be distinguished on the basis of WCST perseverative errors (Bechara et al. 2000). These anatomical and behavioural associations demonstrate that EF and inhibition of impulsivity may require the same resources. Specifically, attentional impulsivity and lack of inhibitory control may correlate with deficits in problem-solving, lack of cognitive flexibility and planning deficits (Bickel et al. 2012).

The cognitive, communicative and emotional consequences of right hemisphere lesions are collected referred to as Right Hemisphere (RH) Syndrome (see Fonseca et al. 2006). Studies of RH syndrome have also uncovered communicative deficits and impairments in EF. Annoni et al. (2003) reported a series of cases that presented such deficits. Gindri et al. (2008) also found impaired executive performance in patients with $\mathrm{RH}$ lesions. It is important to note that this sample did not contain any subjects with damage to the frontal region, indicating that other $\mathrm{RH}$ regions are also involved in EF.
Some authors (Martin and McDonald 2003; Monetta and Champagne 2004) have suggested that the communication deficit associated with $\mathrm{RH}$ damage is due to an EF impairment. Barkley (2001) related EF to problems with communication and social behaviour, and Tompkins et al. (1995) suggested that some of the symptoms of RH lesions, such as impulsivity and communication deficits might be due to impaired inhibition.

Champagne-Lavau and Joanette (2009) showed that individuals with $\mathrm{RH}$ lesion had deficits on inhibitory control tasks and displayed more perseveration behaviour. Impulsivity may be related to inhibitory control and perseveration, which implies that the RH is involved in inhibition of impulsive responses. Fonseca et al. (2006) reported that patients with damage in RH tend to respond quickly and impulsively on behavioural tasks, resulting in poor performance. Taken together these findings suggest that further investigation of EF deficits and impulsivity following RH damage is warranted.

With the evolution of the studies currently understanding of brain function began to be studied based on the associationist theory and cognitive deficits and behavioural changes will depend on the site of injury associated with frontal circuits, parietal cortical temporal and subcortical (Catani et al. 2012). There is a need for further investigation into the cognitive and behavioural changes associated with RH injury. Although RH injuries produce a variety of deficits, research in the $\mathrm{RH}$ has been done just 40 years ago (Côté et al. 2007). Evidence from case studies and groups may contribute to a better understanding of RH syndrome.

The aim of this study was therefore to evaluate EF (problem solving; planning; judgement; cognitive flexibility; inhibitory control) and impulsivity in individuals who had suffered frontal stroke and individuals who had suffered a stroke in the extra-frontal $\mathrm{RH}$. We also analysed the relationship between impulsivity and EF.

\section{Method}

This study was observational, descriptive, cross-sectional and sample was randomised and non-paired whith quantitative data analysis (Creswell 2010).

\section{Participants}

The sample comprised 82 individuals from metropolitan areas, aged between 30 and 79 years old (older individuals were excluded because EF declines with increasing age, Lavarone et al. 2011), who had completed at least four years of education and were fluent in Portuguese. The sample was divided into three groups: (a) patients who had suffered an ischaemic or haemorrhagic stroke in the $\mathrm{RH}$ frontal lobe region (patients with lesions restricted to the primary motor and sensory cortices were excluded) $(n=13)$; (b) patients who had suffered a stroke 
in an extra-frontal $\mathrm{RH}$ region (temporal lobe, parietal lobe, cerebellum and sub-cortical structures; patients with lesions in primary motor and sensory areas were excluded) at least six months ago $(n=31)$; (c) a control group of individuals who had not suffered a stroke $(n=38)$. In all stroke patients lesion location was confirmed with neuroimaging. Groups were matched for educational level (basic education: 4 to 8 years education; high school: 9 to 11 years of education; college $\geq 12$ years of education). The mean time to frontal lesion and extra-frontal net lesion groups was $\mathrm{M}=42.8 \quad( \pm 41.1)$ and $\mathrm{M}=26.2 \quad( \pm 21.6)$, respectively.

The exclusion criteria were: presence of other neurological disease (excluding stroke risk factors); dementia (including vascular dementia); deficits in cognition, motor function, vision, hearing or language that would preclude the subject from completing the research instruments as intended; extremely low IQ $(<70)$; psychiatric disorders, except depression; history of drug addiction or alcoholism. Current or previous participation in neuropsychological rehabilitation programmes and post-stroke psychological treatment were also grounds for exclusion. Patients whose neuroimaging data revealed significant leukoaraiosis, hydrocephalus or brain herniation associated with their stroke or other alterations outside age norms were also excluded. The following term for English were used for screening and controls of variables: a Sociodemographic and Health Questionnaire; Rankin Scale (Rankin 1957); Mini Mental State Exam (MMSE) (Kochhann et al. 2010); SelfReporting Questionnaire (SRQ-20; Gonçalves et al. 2008); WAIS-III Working Memory Index (WMI; Wechsler 1997; Brazilian adaptation and standards: Nascimento, 2004); and Beck Depression Inventory (BDI-II; Beck et al. 1996, adapted and standardised for use in Brazil by Gorenstein et al. 2011).

\section{Cognitive and behavioural tests}

Behavioural Assessment of Dysexecutive Syndrome (BADS; Wilson et al. 1996). We used a translated version adapted for use with Brazilian populations (Macuglia et al. 2012). The BADS is an ecological measure, consisting of six sub-tests assessing cognitive flexibility, problem solving, planning and judgment. The content validity values for all subtests were satisfactory $(>80)$ and the mean kappa coefficient was . 55 .

Wisconsin Card Sorting Test (WCST; Nelson 1976). We used a version adapted and standardised for use in Brazil (Fonseca et al., unpublished manuscript). This version was modified for use with brain-damaged patients and was designed to evaluate problem solving ability. The test consists of 48 letter stimuli in which can be sorted according to colour; shape or number. The instrument has been shown to be sensitive to frontal lobe damage; people with frontal lobe damage tend to make more perseverative errors.

Five Digits Test (Sedó 2007) evaluates inhibitory control via a version of the Stroop effect and used digits divided in four successive parts: decoding; description; inhibition; and displacement. The Spanish version of the test has shown adequate reliability and validity $(>.70)$.

Go/No-Go Task is a computerised task used to evaluate inhibitory motor control (Aron et al. 2004). Participants were instructed to press the space key using their dominant hand as quickly as possible when the letter ' $\mathrm{O}$ ' appeared on the computer screen but were required to avoid pressing the keyboard if the letter ' $V$ ' appeared.

Delay Discounting Task (DDT; Gonçalves 2005) is a computerised task which measures impulsivity in terms of trade-off decisions about the timing and magnitude of a hypothetical reward.

\section{Behavioural scales}

Barratt Impulsivity Scale (BIS-11; Barratt 1959). We used a version adapted and standardised for use in Brazil (Malloy-Diniz et al. 2010). The BIS-11 is a self-report scale, consisting of 30 items to which participants respond using a Likert scale ranging from rarely/never to always/almost always. The BIS-11 evaluates three types of impulsivity: attentional, motor and lack of future planning. The Brazilian version of the test has been shown to have adequate psychometric properties.

Impulsivity Evaluation Scale (ESAVI; Àvila-Batista and Rueda 2011) is a 31-item self-report scale. Responses are given on a five-point Likert scale ranging from $1=$ never to $5=$ always. The scale provides scores for four types of impulsivity: audacity and temerity $(\mathrm{AeT})$, cognitive control (CC), future planning (PF) and lack of concentration and persistence (CeP). Cronbach's alpha for the sub-tests was adequate (.56 to .87), eigenvalues were $>2$ and Kaiser-Meyer-Olkin $(\mathrm{KMO})=0.88$.

\section{Data collection and ethical procedures}

This study was conducted in accordance with the rules laid down by the Psychological Federal Council, Resolution no. 016 (2000) and Regional Health Council Resolution no. 466 (2012) for research on humans. The two clinical groups were recruited consecutively from eligible patients who agreed to participate. Selection of controls was realised through indication of a participant of clinical groups to be included in the study. The order in which participants completed the scales and tasks was varied to avoid order effects. The assessment was performed in two sessions, lasting about $90 \mathrm{~min}$ each, separated by a maximum of two weeks. Assessments took place in the participating hospitals or in the participant's home, in a quiet room with appropriate lighting. 


\section{Data analysis and statistical procedures}

Data were analysed using SPSS version 18.0. First we calculated descriptive statistics such as frequencies, scores, means, medians, standard deviations and tertiles. Nonparametric tests were used because the KolmogorovSmirnov test indicated that variables were not normally distributed and the data included outlier values. Betweengroups comparisons were made using the Kruskal-Wallis test and the Mann-Whitney test was used for post hoc analysis. The Wilcoxon test for non-repetitive measures was used to confirm variability of answers between go/nogo blocks. Spearman's correlation coefficient was used to assess the association between EF and impulsivity. The criterion for significance was set at $p<.05$ for all tests.

\section{Results}

There were no group differences in educational level. The control group differed in age from the frontal lesion group $(U=124.500, z=-2.651, p=.008)$. There were no differences in demographic variables between the control group and the extra-frontal lesion group $(U=484.500, z=-1262$, $p=.207)$ or between the two clinical groups $(U=136.500$, $z=-1673, p=.094)$. The groups were also similar with respect to reading and writing habits, and performance on the MMSE, SRQ-20 and WMI. There was a borderline difference between the control group and the extra-frontal lesion group in depressive symptoms $\left(\chi^{2}(2,82)=5.908\right.$, $p=.052$ ), but the mean level of depressive symptoms was not clinically significant in any of the groups. Data on control variables, sociodemographic variables and health are presented in Table 1.

There were differences between the control group and extra-frontal lesion group with respect to number of WCST trials completed $(U=429.500, z=-2.363, p=.018)$; perseverative errors on the WCST $(U=386.000, z=-2.454$, $p=.014$ ); errors of omission on go/no-go trials with a $1250 \mathrm{~ms}$ ISI $(U=374.500, z=-2.648, p=.008)$ and errors of omission on go/no-go trials with a $1750 \mathrm{~ms}$ ISI $(U=$ $369.500, z=-2.755, p=.006$ ). These results suggest that extra-frontal circuits place a role in certain aspects of $E F$, in particular problem solving and inhibition of impulsivity. Data are exposed in Tables 2 and 3 and Fig. 1.

We assessed between-block differences in errors of omission, errors of commission ad reaction time for the Go/No-Go Task. There was a difference between reaction times on the second and third blocks (1000 ms-1250 ms) and the third and fourth blocks $(1250 \mathrm{~ms}-1750 \mathrm{~ms})$ for the frontal lesion group $(z=-2.062, p=.039)$ and the extra-frontal lesion group $(z=-2.077, p=.038)$. These results indicate that variability in time related to the display interval between a stimulus and its following the various task blocks Go/No-Go did not influence any results in performance in the task, namely the omission of error number and commission.

Scores on the BADS were compared with normative data (Wilson et al. 1996) and used to classify individuals

Table 1 Comparison among the three groups, regarding medians and frequencies of controlled variables

\begin{tabular}{|c|c|c|c|c|c|}
\hline \multirow{3}{*}{ Variables } & \multicolumn{5}{|l|}{ Groups } \\
\hline & Frontal & Extra-Frontal Net & Control & & \\
\hline & Median (tertiles) & Median (tertiles) & Median (tertiles) & $X^{2} N$ & $p$ \\
\hline Scholarity & $11(5.5-17.5)$ & $9(5.0-11.0)$ & $9(5.0-13.0)$ & 2.943 & .230 \\
\hline Age & $64(61.0-71.50)$ & $60(54.0-67.0)$ & $57(47.25-63.50)$ & 7.259 & $.027^{\mathrm{a}}$ \\
\hline Lesion Time & $27.0(23.50-48.0)$ & $22.0(12.0-34.0)$ & - & 143.000 & .132 \\
\hline Rankin Scale & $0(0-1.0)$ & $1.0(0-2.0)$ & - & 147.000 & .126 \\
\hline Reading Habits & $7.0(3.5-8.5)$ & $4.0(2.0-7.0)$ & $5.0(3.0-6.25)$ & 2.552 & .279 \\
\hline Writing Habits & $2.0(0-4.5)$ & $2.0(0-4.0)$ & $3.5(1.0-5.0)$ & 5.185 & .075 \\
\hline \multicolumn{6}{|l|}{ Instruments } \\
\hline MMSE & $29.0(25.50-29.50)$ & $28.0(26.0-29.0)$ & $28.0(26.0-29.0)$ & 1.078 & .583 \\
\hline SRQ-20 & $3.0(2.0-4.50)$ & $4.0(2.0-8.0)$ & $2.0(1.0-5.25)$ & 2.462 & .292 \\
\hline WMI & $27.0(23.50-36.50)$ & $28.0(23.0-34.0)$ & $27.0(24.0-36.25)$ & 0.466 & .921 \\
\hline \multirow[t]{2}{*}{ BDI-II } & $9.0(5.0-12.50)$ & $11.0(4.0-23.0)$ & $6.50(2.0-11.0)$ & 5.908 & .052 \\
\hline & Frequency (\%) & Frequency (\%) & Frequency (\%) & & \\
\hline Males & $8(61,5)$ & $17(54.8)$ & $9(23.7)$ & & \\
\hline Right-handed & $10(76.9)$ & $28(90.3)$ & $34(89.5)$ & & \\
\hline Ischemic Lesion & $10(76.9)$ & $24(77.4)$ & - & & \\
\hline Benzodiazepines & 0 & $4(12.9)$ & $2(5.3)$ & & \\
\hline Antidepressants & $2(15.4)$ & $7(22.6)$ & $4(10.5)$ & & \\
\hline
\end{tabular}

${ }^{a} p \leq 0,05$ comparing control and frontal lesion group 
Table 2 Comparison among the three groups, regarding impulsivity

\begin{tabular}{|c|c|c|c|c|c|}
\hline \multirow[b]{3}{*}{ Variables } & \multicolumn{5}{|l|}{ Groups } \\
\hline & \multirow{2}{*}{$\begin{array}{l}\text { Frontal } \\
\text { Median (tertiles) }\end{array}$} & \multirow{2}{*}{$\begin{array}{l}\text { Extra-Frontal Net } \\
\text { Median (tertiles) }\end{array}$} & \multicolumn{3}{|l|}{ Control } \\
\hline & & & Median (tertiles) & $x^{2}$ & $p$ \\
\hline \multicolumn{6}{|l|}{ Impulsivity Scales } \\
\hline Barrat Total & $58.0(50.50-61.50)$ & $60.0(51.0-66.0)$ & $56.0(50.50-61.0)$ & 2.512 & .285 \\
\hline Attention & $14.0(12.50-17.0)$ & $16.0(13.0-19.0)$ & $15.0(11.0-18.0)$ & 1.109 & .574 \\
\hline Motor & $18.0(17.0-20.50)$ & $19.0(17.0-22.0)$ & $19.0(14.0-21.25)$ & 2.422 & .298 \\
\hline Lack of Planning & $22.0(19.0-26.50)$ & $24.0(21.0-29.0)$ & $23.0(20.0-26.25)$ & 1.646 & .439 \\
\hline ESAVI Total & $93.0(80.50-99.50)$ & $91.0(85.0-93.0)$ & $88.0(84.0-92.25)$ & 1.515 & .469 \\
\hline Concentration \& Persist. & $32.0(22.50-39.50)$ & $31.0(23.0-39.0)$ & $30.0(22.75-34.25)$ & 0.738 & .692 \\
\hline Cognitive Control & $33.0(26.50-37.0)$ & $31.0(25.0-38.0)$ & $32.0(29.0-35.0)$ & 0.195 & .907 \\
\hline Future Planning & $13.0(10.0-15.0)$ & $14.0(11.0-17.0)$ & $14.0(11.0-16.25)$ & 1.037 & .595 \\
\hline Audacy \& Temerity & $18.0(11.50-20.50)$ & $15.0(11.0-17.0)$ & $14.50(12.0-16.25)$ & 2.448 & .294 \\
\hline \multicolumn{6}{|l|}{ Behavioral Impulsivity } \\
\hline DDT-Imp. Choice & $0.500(0.200-0.552)$ & $0.492(0.112-0.576)$ & $0.370(0.11-0.49)$ & 3.521 & .172 \\
\hline \multicolumn{6}{|l|}{ Go/No-Go-Imp. Action } \\
\hline OE1000 & $2.0(0-12.0)$ & $2.0(0-3.0)$ & $1.0(0-3.0)$ & 3.592 & .166 \\
\hline CE1000 & $3.0(1.0-4.0)$ & $2.0(1.0-4.0)$ & $2.0(1.0-3.25)$ & 1.382 & .501 \\
\hline OE1250 & $2.0(1.0-13.0)$ & $3.0(1.0-10.0)$ & $1.0(0-3.0)$ & 7.912 & $.019^{b}$ \\
\hline CE1250 & $3.0(2.0-5.50)$ & $3.0(1.0-4.0)$ & $2.0(1.0-4.0)$ & 1.868 & .393 \\
\hline OE1500 & $1.0(0.50-3.50)$ & $1.0(0-5.0)$ & $0(0-2.25)$ & 2.521 & .284 \\
\hline CE1500 & $2.0(1.0-5.0)$ & $1.0(1.0-4.0)$ & $2.0(0-3.0)$ & 1.718 & .423 \\
\hline OE1750 & $5.0(1.0-13.50)$ & $2.0(0-7.0)$ & $0.50(0-1.25)$ & 11.090 & $.004^{\mathrm{a}}$ \\
\hline CE1750 & $3.0(1.0-6.0)$ & $1.0(0-3.0)$ & $2.0(1.0-4.0)$ & 5.214 & $.074^{b}$ \\
\hline
\end{tabular}

Persist Persistence, Imp Impulsivity, OE.Omission Errors, CE Comission Errors

${ }^{a} p \leq 0,05$ comparing control and frontal lesion group

${ }^{\mathrm{b}} p \leq 0,05$ comparing control and non-frontal lesion group

according to whether or not they exhibited dysexecutive functioning (DF) so as to determine how impulsivity (assessed using a self-report scale and behaviourally, using the Go/No-Go Task) was related to DF in the three groups. In the frontal lesion group, individuals with DF made more errors on $1750 \mathrm{~ms}$ go/no-go trials $(U=4.000$, $z=-1.34, p=.034)$; and in the extra-frontal lesion group, individuals with DF made more errors or omission on $1250 \mathrm{~ms}$ go/no-go trials $(U=37.500, z=-2.22, p=.026)$, $1500 \mathrm{~ms}$ trials $(U=31.000, z=-2.61, p=.011)$ and $1750 \mathrm{~ms}$ trials $(U=37.000, z=-2.25, p=.026)$. These results suggest that DF was associated with errors indicative of impulsive behaviour, especially attentional impulsivity, thus corroborating the findings described above.

Analysis of the correlation between self-reported impulsivity and behavioural measures of EF revealed that, particularly in the extra-frontal lesion group, selfreported impulsivity was negatively associated with cognitive flexibility, cognitive inhibitory control and future planning. Impulsivity was also associated with errors of commission on inhibitory control and flexibility tasks. Performance on flexibility task was strongly correlated with attentional impulsivity and cognitive control. In turn, excess cognitive control appeared to be negatively associated with the performance on EF tasks. In the frontal lesion group there was a correlation between errors on the inhibitory control task - which required cognitive flexibility and $\mathrm{CeP}$ score.

Concerning impulsivity behavioural measures, the extrafrontal net lesion group presented more statistically significant associations. These associations were, most of the time, to the number of omission errors, in all four blocks Go/No-Go Task, and to EF's performance in different subcomponents. Similarly, there were also moderate associations between subcomponent of $\mathrm{EF}$ and errors of omission and commission on the go/no-go task in the frontal lesion group. Tables 4 and 5 and Fig. 2 present the correlations between measures of EF and self-reported or behavioural measures of impulsivity for the two clinical groups.

\section{Discussion}

The extra-frontal lesion group performed worse on the problem solving task than the control group. This task demands cognitive flexibility and strategies to deal with 
Table 3 Comparison among the three groups, regarding executive functions

\begin{tabular}{|c|c|c|c|c|c|}
\hline \multirow[b]{3}{*}{ Variables } & \multicolumn{5}{|l|}{ Groups } \\
\hline & \multirow{2}{*}{$\begin{array}{l}\text { Frontal } \\
\text { Median (tertiles) }\end{array}$} & \multirow{2}{*}{$\begin{array}{l}\text { Extra-Frontal Net } \\
\text { Median (tertiles) }\end{array}$} & \multicolumn{3}{|l|}{ Control } \\
\hline & & & Median (tertiles) & $x^{2}$ & $p$ \\
\hline \multicolumn{6}{|l|}{ Executive Functions } \\
\hline \multicolumn{6}{|l|}{ BADS } \\
\hline Weighted Total & $15.0(11.0-16.50)$ & $15.0(12.0-17.0)$ & $15.0(11.75-17.0)$ & 0.186 & .873 \\
\hline Gross Total & $48.0(43.50-50.0)$ & $51.0(44.0-54.0)$ & $51.0(46.0-55.0)$ & 1.579 & .382 \\
\hline \multicolumn{6}{|l|}{ WCST } \\
\hline Adm. Trials & $48.0(46.0-48.0)$ & $48.0(48.0-48.0)$ & $48.0(40.50-48.0)$ & 5.992 & .050 \\
\hline C. Categories & $3.0(1.0-6.0)$ & $3.0(1.0-5.0)$ & $4.5(2.0-6.0)$ & 5.209 & .074 \\
\hline Ruptures & $0(0-2.0)$ & $0(0-1.0)$ & $0(0-1.0)$ & 0.624 & .732 \\
\hline Hits & $29.0(9.0-37.50)$ & $28.0(15.0-36.0)$ & $35.50(22.75-36.0)$ & 3.666 & .160 \\
\hline Persev. Errors & $14.0(2.50-36.50)$ & $15.0(8.0-29.0)$ & $6.50(1.0-21.25)$ & 6.420 & .040 \\
\hline N. Persev. Errors & $3.0(0-4.0)$ & $4.0(1.0-6.0)$ & $3.0(1.0-6.0)$ & 2.575 & .276 \\
\hline \multicolumn{6}{|l|}{ Five Digits } \\
\hline Inhibition (sec.) & $21.0(16.50-25.0)$ & $25.0(13.0-38.0)$ & $15.0(9.75-22.0)$ & 5.559 & .062 \\
\hline Flexibility (sec.) & $45.0(33.50-51.0)$ & $40.0(25.0-61.0)$ & $38.50(21.75-46.0)$ & 4.778 & .092 \\
\hline Choice Error & $0(0-2.0)$ & $1.0(0-2.0)$ & $0(0-1.0)$ & 1.282 & .527 \\
\hline Alter. Errors & $1.0(0.50-8.0)$ & $2.0(0-4.0)$ & $2.0(0-3.25)$ & 1.146 & .564 \\
\hline
\end{tabular}

Imp. Impulsivity, OE Omission Errors, CE. Comission Errors, Adm. Trials Administered Trials, C. Categories Complete Categories, Persev. Errors Perseverative Errors, N. Persev. Errors Non-Perseverative Errors, Alter. Errors Alternation Errors

${ }^{a} p \leq 0,05$ comparing control and frontal lesion group

${ }^{\mathrm{b}} p \leq 0,05$ comparing control and non-frontal lesion group

the environmental contingence (Nyhus and Barceló 2009), and the extra-frontal lesion group needed more cards to complete the task, as well as making many more perseverative errors. Thus, the test hypothesis of the study was not confirmed; rather the data confirm that extra-frontal regions involved in fronto-cortical and fronto-subcortical circuits - e.g., temporal lobe, parietal lobe, basal ganglia, thalamus and cerebellum - are involved in EF and impulsivity, as indicated by the increase in perseverative errors in this group (Cardinal et al. 2001; Christakou et al. 2004). Persevere's behavior in error tends to hinder the ability of the individual to achieve a goal (Homaifar et al. 2012). Our data suggest that RH extra-frontal regions play a role in EF, which is generally associated with circuits involving frontal regions, particularly $\mathrm{RH}$ frontal regions.

Zelazo's cognitive complexity and control theory posits that $E F$, in particularly the functions which support
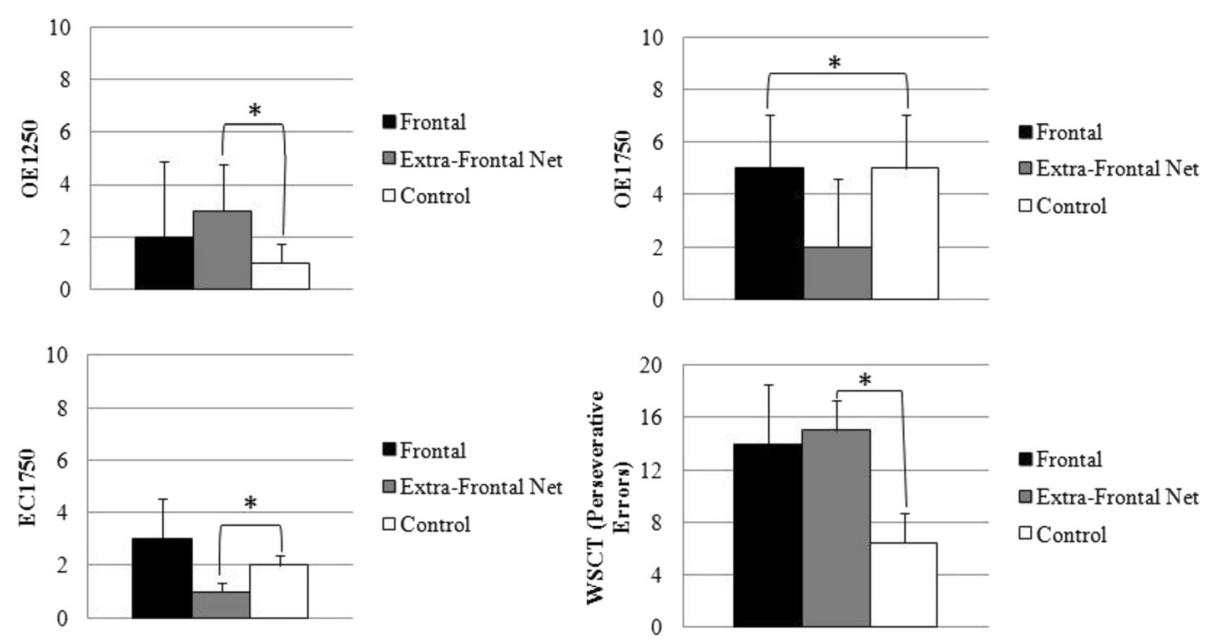

Fig. 1 Comparison among the three groups regarding impulsivity and executive functions for significative results 
Table 4 Correlation measures among impulsivity behavioral tasks and executive functions evaluation tests for both clinical groups

\begin{tabular}{|c|c|c|c|c|c|c|c|c|c|c|}
\hline Task & $\begin{array}{l}\text { WCST } \\
\text { administered } \\
\text { trials }\end{array}$ & $\begin{array}{l}\text { WCST } \\
\text { hits }\end{array}$ & $\begin{array}{l}\text { WCST } \\
\text { perseverative } \\
\text { errors }\end{array}$ & $\begin{array}{l}\text { WCST Non- } \\
\text { perseverative } \\
\text { errors }\end{array}$ & $\begin{array}{l}\text { BADS } \\
\text { weighted }\end{array}$ & $\begin{array}{l}\text { BADS } \\
\text { gross }\end{array}$ & $\begin{array}{l}\text { Five digits } \\
\text { inhibition }\end{array}$ & $\begin{array}{l}\text { Five digits } \\
\text { flexibility }\end{array}$ & $\begin{array}{l}\text { Five digits } \\
\text { choice } \\
\text { errors }\end{array}$ & $\begin{array}{l}\text { Five digits } \\
\text { alternation } \\
\text { errors }\end{array}$ \\
\hline \multicolumn{11}{|l|}{ Go/No-Go } \\
\hline OE1000 & $.30 / .19$ & $-.47 /-.12$ & $.70^{* *} / .17$ & $-.04 / .23$ & $-.06 /-.42^{*}$ & $-.55 /-.45^{*}$ & $-.08 /-.05$ & $.19 /-.12$ & $-.24 / .15$ & $-.36 /-.09$ \\
\hline CE1000 & $-.51 / .09$ & $.65^{*} /-.01$ & $.28 / .04$ & $-.03 /-.05$ & $-.52 /-.12$ & $-.25 /-.14$ & $.07 / .13$ & $-.11 / .05$ & $.54 / .19$ & $.43 /-.09$ \\
\hline OE1250 & $.42 / .32$ & $-.35 / .31$ & $.50 / .38^{*}$ & $-.15 / .23$ & $-.62 * /-.58^{* * *}$ & $-.38 /-.52^{* *}$ & $.20 / .50^{* *}$ & $.34 / .56^{* *}$ & $-.18 / .41^{*}$ & $.33 / .43^{*}$ \\
\hline CE1250 & $-.40 / .08$ & $-.65 * /-.16$ & $.52 / .18$ & $-.06 /-.17$ & $-.15 /-.14$ & $-.23 /-.17$ & $.22 / .20$ & $.03 / .16$ & $.33 / .03$ & $.72 * * / .06$ \\
\hline OE1500 & $-.02 / .34$ & $-.37 /-.37^{*}$ & $.30 / .44^{*}$ & $-.06 /-.20$ & $-.36 /-.60^{* * *}$ & $-.29 /-.52^{* *}$ & $-.19 / .43^{*}$ & $.04 / .44^{*}$ & $-.23 / .51^{* *}$ & $.14 / .42^{*}$ \\
\hline CE1500 & $.05 / .08$ & $-.48 /-.27$ & $.30 / .26$ & $-.37 /-.11$ & $-.22 /-.35$ & $-.30 /-.31$ & $.26 / .44^{*}$ & $-.19 / .45^{*}$ & $.44 / .15$ & $.63 * / .25$ \\
\hline OE1750 & $.06 / .37^{*}$ & $-.48 /-.29$ & $.51 / .37^{*}$ & $-.21 / .21$ & $-.62 * /-.48^{* *}$ & $-.38 /-.47^{* *}$ & $.13 / .39^{*}$ & $.39 / .39^{*}$ & $.13 / .44^{*}$ & $.46 / .33$ \\
\hline CE1750 & $.73^{* * *} /-.15$ & $-.59 * /-.18$ & $.61 * / .19$ & $.0 /-.39^{*}$ & $-.38 /-.02$ & $-.51 /-.02$ & $.31 /-.14$ & $.36 /-.11$ & $.28 /-.22$ & $.64 * / .18$ \\
\hline
\end{tabular}

BADS Behavioural Assessment Dysexecutive Syndrome, WCST Wisconsin Card Sorting Test, OE Omission Errors, OC Comission Errors ${ }^{*} p \leq 0.05 ;{ }^{* *} p \leq 0.01 ;{ }^{* * *} p \leq 0.001$; frontal lesion/extra-frontal lesion

problem solving is not localised to the frontal lobes. Lesions involving the thalamus and basal ganglia may also cause cognitive deficits (Ball et al. 2010), including deficits on the WCST (Liebermann et al. 2013; Mitchell and Chakraborty 2013). The type and severity of cognitive impairments is influenced by lesion size as well as location (Kuceyeski et al. 2011) and caution is needed in interpreting differences between the clinical groups in this study as we did not verify lesion size.

The importance of brain circuits involving parietal lobe in EF was verified through hyper intensity of the white substance in this region, which has been associated with a reduction in EF (Jacobs et al. 2012) and problem solving ability (Hampshire et al. 2008; Hampshire and Owen 2006). The brain functions in a highly connected, interdependent way and non-damaged regions may influence cognitive performance (Catani et al. 2012). Processes essential to EF such as monitoring and selecting information depend on brain circuits which integrate and select information such as the temporal lobe, parietal lobe, striatum and sub-cortical structures (Fuster and Bressler 2012). Evidence indicates that the basal ganglia are part of connected with the frontal cortical regions (Middleton and Strick 2002) and play a role in executive decisions (Opris et al. 2012a, 2012b).

Cognitive flexibility, which is reflected in task switching, encompasses mental processes that enable individuals to reconfigure mental resources. This makes possible to adapt to changes in the environment quickly and effectively (Hampshire and Owen 2006; Loose et al. 2006). The number of brain regions involved suggests that task switching is an aspect of EF which requires the integration of several cognitive operations.

There were group differences in performance on the go/no-go behavioural task, which taps motor and attentional impulsivity. Both clinical groups differed from the control group with respect to errors of omission. When considering the worst performance in the problem solving in comparing the extra-frontal net lesion and control

Table 5 Correlation measures among behavioral scales and executive functions evaluation tests for both clinical groups

\begin{tabular}{|c|c|c|c|c|c|c|c|c|c|c|}
\hline Task & $\begin{array}{l}\text { WCST } \\
\text { administered } \\
\text { trials }\end{array}$ & $\begin{array}{l}\text { WCST } \\
\text { hits }\end{array}$ & $\begin{array}{l}\text { WCST } \\
\text { perseverative } \\
\text { errors }\end{array}$ & $\begin{array}{l}\text { WCST Non } \\
\text { perseverative } \\
\text { errors }\end{array}$ & $\begin{array}{l}\text { BADS } \\
\text { weighted }\end{array}$ & $\begin{array}{l}\text { BADS } \\
\text { gross }\end{array}$ & $\begin{array}{l}\text { Five digits } \\
\text { inhibition }\end{array}$ & $\begin{array}{l}\text { Five digits } \\
\text { flexibility }\end{array}$ & $\begin{array}{l}\text { Five digits } \\
\text { choice errors }\end{array}$ & $\begin{array}{l}\text { Five digits } \\
\text { alternation } \\
\text { errors }\end{array}$ \\
\hline BIS T. & $.15 /-.25$ & $-.14 / .03$ & $.06 /-.05$ & $.12 /-.11$ & $-.04 / .14$ & $.05 / .04$ & $-.23 /-.30$ & $.17 /-.32$ & $.04 / .21$ & $.52 /-.07$ \\
\hline Attent. & $.26 /-.11$ & $-.50 /-.07$ & $.46 / .10$ & $-.09 /-.11$ & $-.08 /-.06$ & $-.29 /-.07$ & $-.07 /-.10$ & $.31 /-.10$ & $.55 / .31$ & $-.0 / .77^{* *}$ \\
\hline Motor & $-.05 /-.08$ & $.13 /-.21$ & $-.14 / .15$ & $-.26 /-.11$ & $-.19 / .22$ & $.13 / .20$ & $.08 /-.29$ & $-.18 /-.34$ & $-.03 / .06$ & $.21 /-.08$ \\
\hline Planning & $-.16 /-.32$ & $.44 / .18$ & $-.44 /-.19$ & $.35 /-.06$ & $-.0 / .24$ & $-.10 / .10$ & $-.17 /-.27$ & $.20 /-.39 *$ & $-.02 / .12$ & $.03 /-.15$ \\
\hline ESAVI T. & $.23 / .16$ & $-.18 /-.26$ & $.15 / 0.24$ & $-.26 / .08$ & $-.23 /-.10$ & $.17 / .04$ & $.25 / .36^{*}$ & $-.04 / .45$ & $.02 / .39^{*}$ & $.22 / .40^{*}$ \\
\hline AeT & $.15 /-.21$ & $.02 / .37^{*}$ & $.06 /-.30$ & $-.21 /-.26$ & $-.06 /-.02$ & $.40 /-.13$ & $.05 / .10$ & $-.41 /-.03$ & $-.08 /-.02$ & $-.05 /-.00$ \\
\hline CC & $.44 / .17$ & $-.15 /-.30$ & $.23 / .26$ & $.02 / .11$ & $.23 /-.23$ & $.28 /-.11$ & $-.05 / .24$ & $-.34 / .50^{* *}$ & $-.02 / .06$ & $-.05 / .38^{*}$ \\
\hline PF & $-.31 / .16$ & $-.34 /-.04$ & $.12 / .10$ & $-.26 /-.06$ & $-.20 /-.21$ & $.10 /-.07$ & $.17 / .16$ & $-.06 / .18$ & $-.15 / .15$ & $-.05 / .17$ \\
\hline CeP & $.33 / .10$ & $-.33 /-.17$ & $.28 / .14$ & $-.13 / .18$ & $-.39 /-.01$ & $-.42 / .08$ & $.20 / .22$ & $.37 / .14$ & $.29 / .41^{*}$ & $.63 * .14$ \\
\hline
\end{tabular}




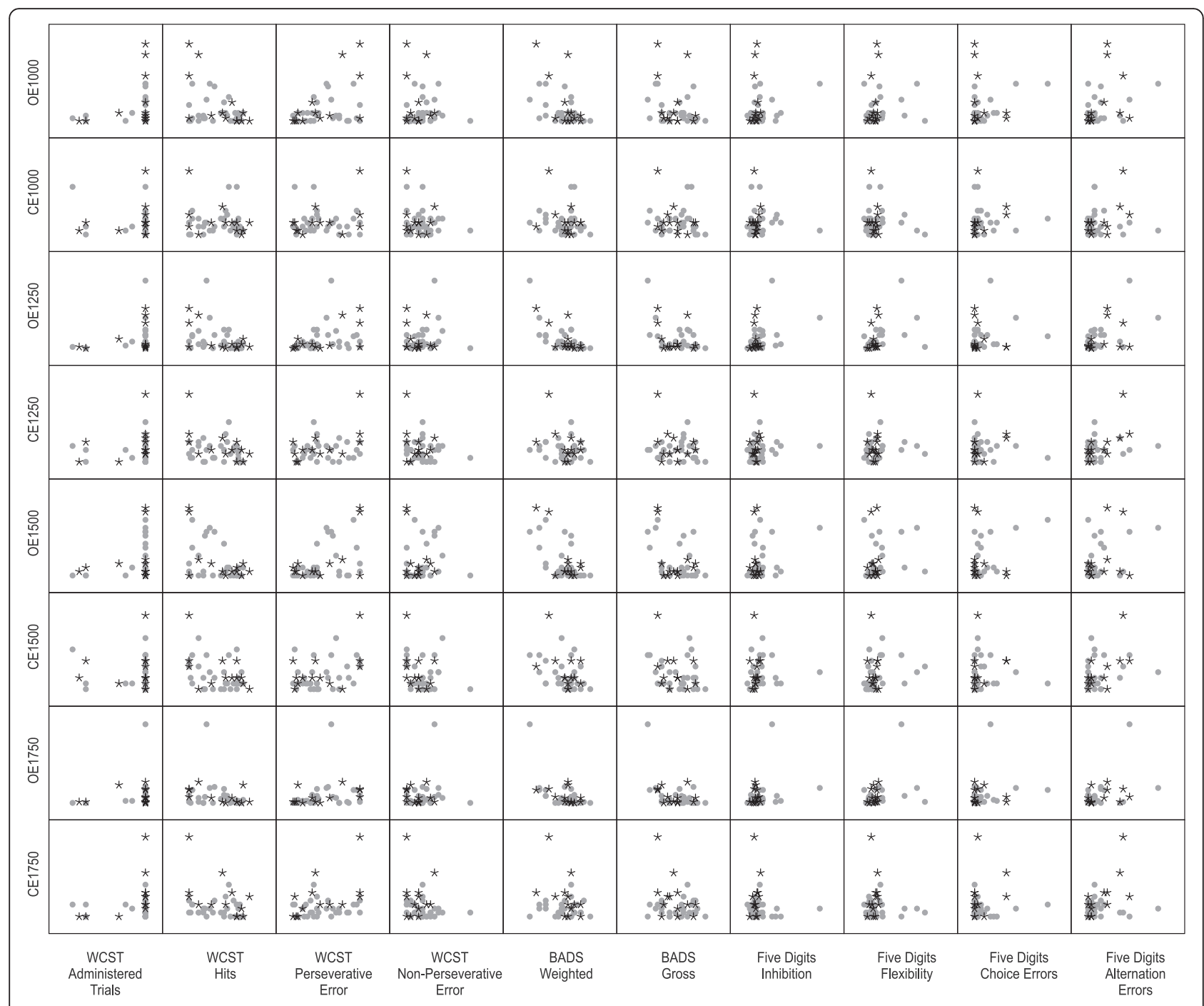

Fig. 2 Correlation matrix among impulsivity and executive functions for both clinical groups (black asterisks = frontal and gray circle = extra-frontal lesion)

group, the behavioural level, task switching is associated with a 'switch cost', for example an increase in the error rate on switch trials relative to repeat trials, which reflects the increased cognitive and attentional demand imposed by switching.

Right ventromedial prefrontal cortex is strongly associated with impulsive control (Boes et al. 2009), but extrafrontal brain regions, such as the amygdale are also involved in impulsive control (Bechara 2005); our data are consistent with these earlier findings. The planning, selection and execution of voluntary actions from among several alternatives is considered a complex behaviour and EF may play an important role in it. A model of the neural circuitry involved in selecting and executing actions, based on behavioural and electrophysiological data from various response inhibition paradigms, has been proposed. This model implies the participation of sub-cortical structures, such as the basal ganglia in a frontal inferior executive control network which integrates information about task rules and thus (Wecki and Frank 2013).

Neuroimaging research has implicated frontal and extra-frontal regions in inhibition of motor responses. Studies have shown that the anterior cingulate cortex (Braver et al. 2001), parietal lobe (Menon et al. 2001), inferior temporal lobe (Rubia et al. 2001) caudate nucleus and cerebellum (Durston et al. 2002) are activated during Go/No-Go Task, indicating that the response inhibition may be associated with the RH (Braver et al. 2001). A study of healthy individuals with normal IQ (Rubia et al. 2003) demonstrated that the right inferior prefrontal region was activated during go/no-go performance, by subtracting activity on no-go trials on which inhibitory control failed from trials on which it was applied successfully. Extra-frontal circuits, involving anterior cingulate cortex and right inferior parietal lobe were implicated in inhibitory control. Anterior cingulate activity was related to 
the number of errors, whereas the parietal region was related to preparation and execution of the motor response and to errors of commission on no-go trials. Further evidence for the involvement of extra-frontal regions in inhibitory control was provided by a study of patients with Parkinson's disease which showed that the sub-thalamic nucleus was involved in the inhibition of responses on the Go/No-Go Task (Hershey et al. 2010).

Analysis of the correlations between self-reported impulsivity and performance on EF tasks indicated that the cognitive flexibility is important for planning and cognitive inhibitory control, especially among the extrafrontal net lesion group. These results are consistent with an earlier study suggesting that structures outside the frontal region, such as the right inferior temporal gyrus are involved in planning and control of impulsivity (Schilling et al. 2012). It seems that impulsivity in extrafrontal lesions individuals influences performance on tasks requiring EF or inhibitory control, particularly at the cognitive level. Previous authors have reported correlations between score on self-report scales intended to assess impulsivity, such as BIS 11, and EF (Horn et al. 2003; Reynolds et al. 2006). Impulsive behaviour may represent a failure to inhibit an action with negative consequences, and may reflect a lack of planning, impaired decisionmaking and tendency to fast action (Alvarez-Moya et al. 2011). Impulsivity is reflected in errors of commission on inhibitory control tasks and executive flexibility tasks.

This result suggests that the lack of attention, arising from impulsive behaviour, may have a negative impact on an individual's ability to adapt to changes in contingency and to benefit from feedback. Attentional impulsivity is reflected in errors of omission on go/no-go tasks and tends to be higher among clinical groups (MalloyDiniz et al. 2007). The relationship between cognitive and motor inhibition is not yet clear, but cognitive inhibition appears to mediate attentional processes whereas motor inhibition is related to behaviour such as response inhibition and delayed gratification (Kipp 2005). We found no difference between the control group and the clinical groups with respect to decisions about delaying gratification, suggesting that attentional impulsivity can be dissociated from aspects of impulsive behaviour, especially in the extra-frontal lesion group.

Excessive cognitive control can also have a negative influence on performance on EF tasks, perhaps due to intensive use of resources for planning and deliberations; this might explain the positive association between cognitive flexibility and performance on tasks requiring inhibitory control (Àvila-Batista and Rueda 2011). Our data are consistent with this suggestion as the performance of the extra-frontal lesion group on the behavioural inhibition task suggests that attentional control is required to inhibit inappropriate responses. It appears that
EF (i.e., planning and problem solving - which demands cognitive flexibility - and temporal judgment) is negatively associated with errors of omission related to impulsive behaviour. Inability to inhibit internal representations of incorrect responses contributes to WCST poor performance, resulting in difficulty in changing strategies and perseveration errors (Vendrell et al. 1995). The cognitive flexibility may represent necessary step towards successful control of voluntary or automatic responses.

In the frontal lesion group inhibitory control was negatively correlated with concentration and persistence, and with the motor and attentional aspects of impulsivity. This suggests that the impact of lack of attentional focus, which may be reflected in the number of errors on the Go/NoGo task, may be magnified by lack of persistence and by distractibility, both of which are consequences of impulsive behaviour (Àvila-Batista and Rueda 2011). This constitutes further evidence that attentional processes are involved in EF. Our data on impulsivity indicate that it is a multidimensional phenomenon and that individuals with vascular injury to the RH may result in increased impulsivity, accompanied by selective EF deficits.

Previous research has implicated the middle frontal gyrus (MFG) in top-down control of attentional and executive processes. Along with the superior frontal gyrus (SFG) and the orbitofrontal region, MFG seem to be involved in mediating inhibitory behaviour after $\mathrm{RH}$ stroke (Kopp et al. 2013), and in planned actions and attention (Schilling et al. 2012). The similarity of rates of errors of omission and commission when switching from one trial type to another on the Go/No-Go Task suggests that there were no behaviour alteration arising from the change from the trials and suggests that the results do not arise from variables that may interfere in go/no-go performance, as fatigue, for example. It is, however, important to note that these results were based on a small sample of frontal lesion patients; the small sample may have masked real group differences in impulsive behaviour and EF.

In both clinical groups individuals considered to show DF based on BADS scores showed more errors of omission on the Go/No-Go Task, especially those in the extra-frontal lesion group. These relationships indicate that individuals with an extra-frontal lesion may display DF and that DF is strongly associated with aspects of impulsivity. There is evidence that EF and impulsivity are related (Kam et al. 2012), and show higher attentional impulsivity in impulsive action associated with EF's performance, in a way that, the higher the dysfunction, the higher the impulsivity.

\section{Conclusion}

This study showed that frontal and extra-frontal regions in networks comprising the $\mathrm{RH}$ frontal lobes are involved in EF, especially problem solving and cognitive flexibility. Lesions in frontal regions and in extra-frontal 
circuits seem to be involved in the lack of inhibitory control, especially inhibition of impulsive action. Besides from the participation of external regions in frontal region in concerning EF's performance and impulsivity, they seem to be crucial in the association between performance cognitive and behavioural aspects.

\section{Competing interests}

The authors declare that they have no competing interests.

\section{Authors' contributions}

MS participated in all stages of the study, from the preparation of its design, data collection and analysis and writing of the final article; CK, BGS and LAK participated in the data collection and writing of the final article. RGO contributed to the discussion of the work and data analysis and RMMA contributed to the orientation of the project and to carry out the work, as well as its final writing. All authors read and approved the final manuscript

\section{Author details}

'Universidade Federal do Rio Grande do Sul-UFRGS, Porto Alegre, Brazil. ${ }^{2}$ Universidade do Vale do Rio dos Sinos-UNISINOS, São Leopoldo, Brazil. ${ }^{3}$ Pontifícia Univesidade Católica do Rio Grande do Sul-PUCRS, Porto Algre, Brazil.

\section{Received: 15 March 2016 Accepted: 7 April 2016}

Published online: 21 April 2016

\section{References}

Adinoff B, Rilling LM, Williams MJ, Schreffler E, Schepis TS, Rosvall T, Rao U. Impulsivity, neural deficits, and the addictions: the "oops" factor in relapse. J Addict Dis. 2007;26(I1):25-39. doi:10.1300/J069v26S01_04.

Alvarez-Moya EM, Ochoa C, Jiménez-Murcia S, Aymamí MN, Gómez-Peña M, Fernández-Aranda F, Santamaría J, Moragas L, Bove F, Menchón JM. Effect of executive functioning, decision-making and self-reported impulsivity on the treatment outcome of pathologic gambling. J Psychiatry Neurosci. 2011; 36(3):165-75. doi:10.1503/jpn.090095

Annoni JM, Khateb A, Gramigna S, Staub F, Carota A, Maeder P, Bogousslavsky J. Chronic cognitive impairment following laterothalamic infarcts: a study of 9 cases. Arch Neurol. 2003;60(10):1439-43. doi:10.1001/archneur.60.10.1439.

Aron AR, Robbins TW, Poldrack RA. Inhibition and the right inferior frontal cortex. Trends Cogn Sci. 2004;8:170-7. doi:10.1016/tics.2004.02.010.

Àvila-Batista AC, Rueda FJM. Construção e estudos psicométricos de uma Escala de Avaliação da Impulsividade. Psico-USF. 2011;16(3):285-95. doi:10.1590/ S1413-82712011000300005.

Ball SL, Holland AJ, Watson PC, Huppert FA. Theoretical exploration of the neural bases of behavioural disinhibition, apathy and executive dysfunction in preclinical Alzheimer's disease in people with Down's syndrome: Potential involvement of multiple frontal-subcortical neuronal circuits. J Intellect Disabil Res. 2010;54(4):320-36. doi:10.1111/j.1365-2788.2010.01261.x.

Barkley RA. The executive functions and self-regulation: an evolutionary neuropsychological perspective. Neuropsychol Rev. 2001;11:1-29. Retrieved in September 17, 2015, from http://www.ncbi.nlm.nih.gov/pubmed/?term=The +executive+functions+and+self-regulation\%3A+an+evolutionary +neuropsychological+perspective.

Barratt ES. Anxiety and impulsiveness related to psychomotor efficiency (L. F. Malloy-Diniz, P. Mattos, W. B. Leite, N. Abreu, G. Coutinho, J. J. Paula, H. Tavares, A. G. Vasconcelos, \& D. Fuentes, Adaptação e validação brasileira para adultos, 2010). Percept Mot Skills. 1959;9:191-8. doi:10.1590/S151644462006005000020

Barratt ES. Impulsiveness and aggression. In J. Monahan, \& H. Steadman (Eds.), Violence and Mental Disorder: Developments in Risk Assessment Chicago: University of Chicago Press; 1994.

Bartolomeu P. The quest for the 'critical lesion site' in cognitive deficits: Problems and perspectives. Cortex. 2011;47(8):1010-2. doi:10.1016/j.cortex.2010.11.007.

Bechara A. Decision making, impulse control and loss of willpower to resist drugs: a neurocognitive perspective. Nat Neurosci. 2005:8(11):1458-63. doi:10.1038/nn1584.

Bechara A, Tranel D, Damasio H. Characterization of the decision making deficit of patients with ventromedial prefrontal cortex lesions. Brain. 2000;123:2189-202. doi:10.1093/brain/123.11.2189.
Beck AT, Steer RA, Brown GK, editors. Manual for Beck Depression Inventory-II (C Gorenstein, W. Y. Pang, I. L. Argimon, \& B. S. G. Werlang, Adaptação e padronização brasileira, 2001). San Antonio, TX: Psychological Corporation; 1996.

Bickel WK, Jarmolowicz DP, Mueller ET, Gatchalian KM, McClure SM. Are executive function and impulsivity antipodes? A conceptual reconstruction with special reference to addiction. Psychopharmacology. 2012;222(3):361-87. doi:10. 1007/s00213-012-2689-x.

Bilder RM. Executive control: Balancing stability and flexibility via the duality of evolutionary neuroanatomical trends. Dialogues Clin Neurosci. 2012;14(1):39-47. Retrieved in February 15, 2015, from http://www.ncbi.nlm.nih.gov/pmc/articles/ PMC3341648/pdf/DialoguesClinNeurosci-14-39.pdf.

Boes AD, Bechara A, Tranel D, Anderson SW, Richman L, Nopoulos P. Right ventromedial prefrontal cortex: A neuroanatomical correlate of impulse control in boys. Soc Cogn Affect Neurosci. 2009;4(1):1-9. doi:10.1093/scan/nsn035.

Braver TS, Barch DM, Gray JR, Molfese DL, Snyder A. Anterior cingulate cortex and response conflict: effects of frequency, inhibition and errors. Cereb Cortex. 2001;11(9):825-36. doi:10.1093/cercor/11.9.825.

Brenan P, Raine A. Biosocial bases of antisocial behavior: Psychophysiological, neurological, and cognitive factors. Clin Psychol Rev. 1997;17(6):589-604. doi:10.1016/S0272-7358(97)00036-6.

Broos N, Schmaal L, Wiskerke J, Kostelijk L, Lam T, Stoop N, Weierink L, Goudriaan AE. The relationship between impulsive choice and impulsive action: A crossspecies translational study. Plos One. 2012;7(5):e36781. doi:10.1371/journal. pone.0036781. Retrieved in January 23, 2015, from http://www.ncbi.nlm.nih. gov/pmc/articles/PMC3344935/pdf/pone.0036781.pdf.

Cardinal RN, Pennicott DR, Sugathapala CL, Robbins TW, Everitt BJ. Impulsive choice induced in rats by lesions of the nucleus accumbens core. Science. 2001;292(5526):2499-501. doi:10.1126/science.1060818.

Catani M, Dell'Acqua F, Bizzi A, Forkel S, Williams S, Simmons A, Murphy D, Thiebaut de Schotten M. Beyond cortical localisation in clinico-anatomical correlation. Cortex. 2012;1-25. doi:10.1016/j.cortex.2012.07.001

Champagne-Lavau M, Joanette Y. Pragmatics, theory of mind and executive functions after a right-hemisphere lesion: different patterns of deficits. J Neurolinguistics. 2009;22:413-26. doi:10.1016/j.jneuroling.2009.02.002.

Cheung AM, Mitsis EM, Halperin JM. The relationship of behavioral inhibition to executive functions in young adults. J Clin Exp Neuropsychol. 2004;26(3):393-404. doi:10.1080/13803390490510103.

Christakou A, Robbins TW, Everitt BJ. Prefrontal cortical-ventral striatal interactions involved in affective modulation of attentional performance: implications for corticostriatal circuit function. J Neurosci. 2004;24:773-80 doi:10.1523/JNEUROSCI.0949-03.2004

Côté H, Payer M, Giroux F, Joanette Y. Towards a description of clinical communication impairment profiles following right-hemisphere damage. Aphasiology. 2007;21(6/8):739-49. doi:10.1080/02687030701192331.

Creswell JW. Projeto de Pesquisa Métodos Qualitativo, Quantitativo e Misto. 3ath ed. Porto Alegre: Artes Médicas; 2010.

Diamond A. Executive functions. Anual RevPsychol. 2013;64:135-68. doi:10.1146/ annurev-psych-113011-143750.

Durston S, Thomas KM, Worden MS, Yang Y, Casey BJ. The effect of preceding context on inhibition: An event-related fMRI study. Neuroimage. 2002;453(2): 449. doi:10.1006/nimg.2002.1074.

Fonseca RP, Ferreira GD, Liedtke FV, Müller JL, Sarmento TF, Parente MAM. Alterações cognitivas, comunicativas e emocionais após lesão hemisférica direita: Em busca de uma caracterização da Síndrome do Hemisfério Direito. Psicol USP. 2006;17(4):241-62. doi:10.1590/S0103-65642006000400013.

Fuster JM, Bressler SL. Cognit activation: a mechanism enabling temporal integration in working memory. Trends Cogn Sci. 2012;16(4):207-18. doi:10.1016/j.tics.2012.03.005.

Gindri G, Zibetti MR, Fonseca RP. Funções executivas pós-lesão de hemisfério direito: estudo comparativo e freqüência de déficits. PSICO. 2008:39(3):282-29. Retrieved in September 15, 2015, from http://revistaseletronicas.pucrs.br/ojs/ index.php/revistapsico/article/view/3901/3371.

Gonçalves FL. Desvalorização pelo atraso em situações apetitivas e aversivas (dissertação de doutorado não publicada). Programa de Pós-Graduação em Psicologia, Instituto de Psicologia. Brasil: Universidade de São Paulo; 2005.

Gonçalves DM, Stein AT, Kapczinski F. Avaliação de desempenho do Self-Reporting Questionnaire como instrumento de rastreamento psiquiátrico: Um estudo comparativo com o Structured Clinical Interview for DSM-IV-TR. Caderno de Saúde Pública. 2008;24(2):380-90. doi:10.1590/S0102-311X2008000200017.

Gorenstein, C, Pang WY, Argimon IL, Werlang BSG. Escala Beck de Depressão-II. Manual. São Paulo, SP: Casa do Psicólogo; 2011. 
Hampshire A, Owen AM. Fractionating attentional control using event related fMRI. Cereb Cortex. 2006;16(12):1679-89. doi:10.1093/cercor/bhj116.

Hampshire A, Gruszka A, Fallon SJ, Owen AM. Inefficiency in self organized attentional switching in the normal aging population is associated with decreased activity in the ventrolateral prefrontal cortex. J Cogn Neurosci. 2008;20(9):1670-86. doi:10.1162/jocn.2008.20115.

Hershey T, Campbell MC, Videen TO, Lugar HM, Weaver PM, Hartlein J, Karimi M, Perlmutter JS. Mapping Go-No-Go performance within the subthalamic nucleus region. Brain. 2010;133(Pt 12):3625-34. doi:10.1093/brain/awq256.

Homaifar BY, Brenner LA, Forster JE, Nagamoto H. Traumatic brain injury, executive functioning, and suicidal behavior: a brief report. Rehab Psychol. 2012;57(4):337-41. doi:10.1037/a0030480.

Horn NR, Dolan M, Elliott R, Deakin JF, Woodruff PW. Response inhibition and impulsivity: An fMRI study. Neuropsychologia. 2003;41:1959-66. doi:10.1016/ S0028-3932(03)00077-0.

Jacobs HIL, Visser PJ, Van Boxtel MPJ, Frisoni GB, Tsolaki MPP, Nobili F, Verhey FRJ. The association between white matter hyperintensities and executive decline in mild cognitive impairment is network dependent. Neurobiol Aging. 2012;33(1):1-8. doi:10.1016/j.neurobiolaging.2010.07.015.

Jodzio K, Biechowska D. Wisconsin card sorting test as a measure of executive function impairments in stroke patients. Appl Neuropsychol. 2010;17(4):267-77. doi:10.1080/09084282.2010.525104.

Jurado MB, Rosselli M. The elusive nature of executive functions: A review of four current understanding. Neuropsychol Rev. 2007;17(3):213-33. doi:10.1007/ s11065-007-9040-z.

Kam JW, Domonelli R, Carlson SR. Differential relationships between subtraits of BIS-11 impulsivity and executive processes. International Journal of Psychophysiology. 2012;85:174-87. doi:10.1016/j.ijpsycho. 2012.05.006.

Kipp K. A developmental perspective on the measurement of cognitive deficits in attention-deficit/hyperactivity disorder. Biological Psychiatry. 2005;57:1256-60. doi:10.1016/j.biopsych.2005.03.012.

Kluwe-Schiavon B, Viola TW, Grassi-Oliveira R. Modelos teóricos sobre construto único ou múltiplos processos das funções Executivas. Rev Neuropsicol Latinoam. 2012;4(2):29-34. doi:10.5579/rnl.2012.00106.

Kochhann R, Varela JS, Lisboa CSM, Chaves MLF. The Mini Mental State Examination review of cutoff points adjusted for schooling in a large Southern Brazilian sample. Dement Neuropsychol. 2010;41:35-41. doi:10.1159/000017231

Kopp B, Rösser N, Tabeling S, Stürenburg HJ, de Haan B, Karnath HO, Wessel K. Performance onthe Frontal Assessment Battery is sensitive to frontal lobe damage in stroke patients. BMC Neurol. 2013;13:179. doi:10.1186/1471-2377-13-179.

Krause M, Mahant N, Kotschet K, Fung VS, Vagg D, Wong CH, Morris JGL. Dysexecutive behaviour following deep brain lesions: A different type of disconnection syndrome? Cortex. 2012;48:97-119. doi:10.1016/j.cortex.2011.03.014.

Kuceyeski A, Maruta J, Niogi SN, Ghajar J, Raj A. The generation and validation of white matter connectivity importance maps. Neuroimage. 2011;58(1):109-21. doi:10.1016/j.neuroimage.2011.05.087.

Lavarone A, Lorè E, De Falco C, Milan G, Mosca R, Pappatà S,Galeone F, Postiglione A. Dysexecutive performance of healthy oldest old subjects on the Frontal Assessment Battery. Aging clinical and experimental research. Aging Clin Exp Res. 2011;23(5-6):351-6. doi:10.3275/7809.

Li N, Ma N, Liu Y, He XS, Sun DL, Fu XM, Zhang X, Han S, Zhang DR. Resting-state functional connectivity predicts impulsivity in economic decision-making. J Neurosci 13. 2013;33(11):4886-95. doi:10.1523/JNEUROSCI.1342-12.2013.

Liebermann D, Ploner CJ, Kraft A, Kopp UA, Ostendorf F. A dysexecutive syndrome of the medial thalamus. Cortex. 2013;1:40-9. doi:10.1016/j.cortex.2011.11.005.

Loose R, Kaufmann C, Tucha O, Auer DP, Lange KW. Neural networks of response shifting: influence of task speed and stimulus material. Brain Res. 2006;1090: 146-55. doi:10.1016/j.brainres.2006.03.039.

Macuglia GR, Rieder CRM, de Almeida RMM. Avaliação das Funções Executivas e Aspectos do Humor na Doença de Parkinson. Psico. 2012;43(4):552-61.

Malloy-Diniz LF, Fuentes D, Leite WB, Correa H, Bechara A. Impulsive behavior in adults with attention deficit-hyperactivity disorder: Characterization of attentional, motor and cognitive impulsiveness. JINS. 2007;13(4):693-8. doi:10.1017/S1355617707070889.

Malloy-Diniz LF, Mattos P, Leite WB, Abreu N, Coutinho G, Paula JJ, Tavares H, Vasconcelos AG, Fuentes D. Tradução e adaptação cultural da Barratt Impulsiveness Scale (BIS-11) para aplicação em adultos brasileiros. Jornal Brasileiro de Psiquiatria. 2010:59:99-105. https://dx.doi.org/10.1590/5004720852010000200004.
Martin I, McDonald S. Weak coherence, no theory of mind, or executive dysfunction? Solving the puzzle of pragmatic disorders. Brain Lang. 2003;85: 451-66. doi:10.1016/S0093-934X(03)00070-1.

Menon V, Adleman NE, White CD, Glover GH, Reiss AL. Error related brain activation during a Go/NoGo response inhibition task. Hum Brain Mapp. 2001;12(3):131-43. doi:10.1002/1097-0193(200103)12:3<131.

Middleton FA, Strick PL. Basal ganglia 'projections' to the prefrontal cortex of the primate. Cerebral Cortex. 2002;12:926-45. doi:10.1093/cercor/12.9.926.

Mitchell AS, Chakraborty S. What does the dorsal thalamus do? Frontiers in Systems Neuroscience. 2013;7:37. doi:10.3389/fnsys.2013.00037. Retrieved in December 21, 2014, from http://www.ncbi.nlm.nih.gov/pmc/articles/ PMC3738868/pdf/fnsys-07-00037.pdf.

Monetta L, Champagne M. Processus cognitifs sous-jacents déterminant les troubles de la communication verbale chez les cérébrolésés droits. Réeducation Orthophonique. 2004;219:27-41. Retrieved in September 11, 2015, from http:// www.orthoedition.com/medias/fichiers/2011-01-10-10-12-26_2526824.pdf.

Nascimento E. WAIS-III: Escala Wechsler de Inteligência para Adultos-manual técnico. São Paulo, SP: Casa do Psicólogo; 2004.

Nelson HE. A modified card sorting test sensitive to frontal lobe defects. Cortex. 1976;12:313-24.

Nyhus E, Barceló F. The Wisconsin card sorting test and the cognitive assessment of prefrontal executive functions: a critical udate. Rain Cgnition. 2009;74:437-57. doi:10.1016/j.bandc.2009.03.005.

Opris I, Hampson RE, Gerhardt GA, Berger TW, Deadwyler SA. Columnar processing in primate pFC: Evidence for executive control microcircuits. J Cogninite Neurosci. 2012a;24(12):2334-47. doi:10.1162/jocn_a_00307.

Opris I, Fuqua JL, Huett PF, Gerhardt GA, Berger TW, Hampson RE, Deadwyler SA. Closing the loop in primate prefrontal cortex: Inter-laminar processing. Frontiers in Neural circuits. 2012b;6:88. doi:10.3389/fncir.2012.00088. Retrieved in January 28, 2015, from http://www.ncbi.nlm.nih.gov/pmc/articles/ PMC3504312/pdf/fncir-06-00088.pdf.

Radanovic M, Mansur LL. Contribution to the evaluation of language disturbances in subcortical lesions: A piloty study. Arquivos de Neuropsiquiatria. 2004;62(1):51-7. 10.1590/S0004-282X2004000100009.

Rankin J. Cerebral vascular accidents in patients over the age of 60. II. Prognosis. Scott Med J. 1957;2(5):200-15.

Reynolds B, Ortengren A, Richards JB, de Wit H. Dimensions of impulsive behavior: personality and behavioral measures. Personal Individ Differ. 2006; 40:305-15. doi:10.1037/1064-1297.16.2.124.

Robinson H, Calamia M, Gläscher J, Bruss J, Tranel D. Neuroanatomical correlates of executive functions: a neuropsychological approach using the examiner battery. J Int Neuropsychol Soc. 2014;20:52-63. doi:10.1017/S135561771300060X.

Rubia K, Russell T, Overmeyer S, Brammer MJ, Bullmore ET, Sharma T, Taylor E. Mapping motor inhibition: conjunctive brain activations across different versions of go/nogo and stop tasks. Neuroimage. 2001;13(2):250-61. doi:10.1006/nimg.2000.0685.

Rubia K, Smith AB, Brammer MJ, Taylor E. Right inferior prefrontal cortex mediates response inhibition while mesial prefrontal cortex is responsible for error detection. Neuroimage. 2003;20(1):351-8. doi:10.1016/S1053-8119(03)00275-1.

Schilling C, Kühn S, Romanowski A, Schubert F, Kathmann N, Gallinat J. Cortical thickness correlates with impulsiveness in healthy adults. Neuroimage. 2012; 59(1):824-30. doi:10.1016/j.neuroimage.2011.07.058.

Sedó M. FDT-Test de los Cinco Digitos. Madrid, Spain: TEA Ediciones; 2007.

Seeley WW, Menon V, Schatzberg AF, Keller J, Glover GH, Kenna H, Greicius MD. Dissociable intrinsic connectivity networks for salience processing and executive control. J Neurosci. 2007;27:2349-56. doi:10.1523/JNEUROSCI.5587-06.2007.

Stuss DT, Levine B. Adult clinical neuropsychology: lessons from studies of the frontal lobes. Annu Rev Psychol. 2002;53:401-33. doi:10.1146/annurev.psych. 53.100901.135220.

Thiebaut de Schotten M, Dell'Acqua F, Valabregue R, Catani M. Monkey to human comparative anatomy of the frontal lobe association tracts. Cortex. 2012:48(1):81-95. doi:10.1016/j.cortex.2011.10.001.

Tompkins CA, Baumgaertner A, Lehman MT, Fossett TRD. Suppression and discourse comprehension in rightbrain-damaged adults. Brain Lang. 1995:51:181-3.

Vendrell P, Junqué C, Pujol J, Jurado MA, Molet J, Grafman J. The role of prefrontal regions in the Stroop task. Neuropsychologia. 1995;33(3):341-52. doi:10.1016/0028-3932(94)00116-7.

Wechsler D. Wechsler Adult Intelligence Scale-III (WAIS-III) (E, Nascimento, Adaptação e validação brasileira, 2004). San Antonio, TX: The Psychological Corporation: Copyright; 1997.

Wecki TV, Frank MJ. A computational model of inhibitory control in frontal cortex and basal ganglia. Psychol Rev. 2013;120(2):329-55. doi:10.1037/a0031542. 
Whitney P, Jameson T, Hinson JM. Impulsiveness and executive control of working memory. Pers Individ Differences. 2004;37:417-28.

Wilson BA, Alderman N, Burguess PW, Emslie H, Evans JJ. Behavioural Assessment of the Dysexecutive Syndrome (BADS). Bury St Edmunds, UK: Thames Valley Test Company; 1996.

Zappalá G, Thiebaut de Schotten M, Eslinger PJ. Traumatic brain injury and the frontal lobes: What can we gain with diffusion tensor imaging. Cortex. 2012; 46(2):156-65. doi:10.1016/j.cortex.2011.06.020.

\section{Submit your manuscript to a SpringerOpen ${ }^{\odot}$ journal and benefit from:}

- Convenient online submission

- Rigorous peer review

- Immediate publication on acceptance

- Open access: articles freely available online

- High visibility within the field

- Retaining the copyright to your article

Submit your next manuscript at $>$ springeropen.com 